Medicine Updates Faculty of medicine October 2021,volume 7, issue 7 https://muj.journals.ekb.egdean@med.psu.edu.eg vice_dean_postgraduate@med.psu.edu.eg

DOI: 10.21608/MUJ.2021.96037.1065

ISSN : 2682-2741

Submitted: $41 / 9 / 2021$

Accepted : 42/9/2021

Pages:.89-102

\title{
" Effects of Quality Tools Implementation on Reducing the Risk of Ventilator Associated Pneumonia at El - Mabarah Hospital in Port said Governorate "
}

\section{Authors}

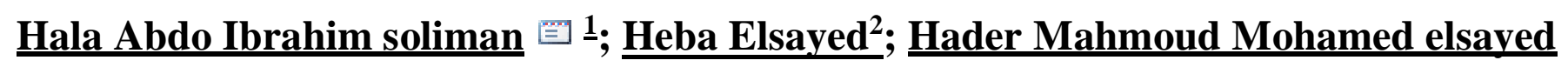

Ahmed Elzaghawy33; Basma Gamal Mohamed mokhtar Mohamed Ibrahim

hetemi ${ }^{4}$; Gehad Reda Mohamed Abdel Fattah ${ }^{5}$; Asmaa Mohamed Ewies

$\underline{\text { Ahmed }}^{6}$; Norhan Yasser Al-Tamimi Fahmy Gharbih $^{7}$; $\underline{\text { Norhan Tarek Mohamed Jamal }}$

Eltawel $^{7}$

${ }^{1}$ faculty of nursing in port said

${ }^{2}$ Port Said University

${ }^{3}$ Faculty of Nursing at Port Said University Complete the study of master degree in nursing administration in faculty of Nursing at Port Said University Attain ministry training for infection control Attain ICDL course

Attain the toeful course

${ }^{4}$ Faculty of pharmacy -Egyptian Russian university

${ }^{5}$ A graduate of a health institute And complete the Faculty of Nursing Ain Shams University

${ }^{6}$ Faculty of Nursing at Port Said University

${ }^{7}$ Faculty of Nursing Ain Shams University

Abstract:

Background:

VAP is still one of the problems facing hospitals and increases the risk of Nosocomial infection (1).

VAP has a close association with increased attributable deaths (2).

The most common risk factor to VAP the aspiration of contaminated pharyngeal,

Accumulation of secretions in the endotracheal tube, Tubes with cuffs made of polyurethane 
rather than polyvinyl chloride (3).

\section{METHODS:}

- Check list

- Flow chart

Conclusion :- IMPROVE HEALTH CARE.

- The aim to Establishment of quality standards tools to reduce the risk of Ventilator association pneumonia.

- Implementation of policy and procedures for reducing the Risk of VAP.

\section{Keywords :}

Quality tools - reduce the risk of VAP - Ventilator association pneumonia - intensive car 


\section{Introduction}

Hospital-acquired pneumonia (HAP) is the most common infection in the intensive care unit (ICU). This infection includes two different pathways:

- Ventilator-associated pneumonia (VAP): pneumonia associated with mechanical ventilation

\section{- Severe pneumonia developed during the hospital stay (HAP)}

The incidence of VAP ranges from 1.9 to 3.8 per 1000 days of mechanical ventilation in the US and exceeds 18 per 1000 days of mechanical ventilation in Europe. (Koulenti D, Tsigou E, Rello J, 2016).

Nosocomial pneumonia is the most common infection in ICU, when considering the timing of these infections. Non-ventilator (HAP) occurs in patients admitted to the hospital for at least 48 hours and VAP is defined as occurring more than 48 hours after the initiation of mechanical ventilation. Accurate data on their epidemiology are limited by the lack of standardised diagnostic criteria.

In the US, the incidence of HAP was $1.6 \%$, representing a rate of 3.63 per 1000 patient-days (Giuliano .KK, Baker. D, Quinn .B,2017). ${ }^{(4)}$

Quality improvement (QI) in originations does special efforts to enhance the quality of care and customer outcomes (Finney et al. 2000; Chong et al. 2003; Raposo et al. 2009; Lee et al. 2012). ${ }^{(5)}$

The process of QI requires the active use of management quality tools by organization managers to improve the quality of production.

Recently, there are many quality management tools, so selecting the appropriate tools is not always easy (Krakowiak-Bal and Salamon, 2011).

Statistics has a unique place in the modern society (Máchal et al., 2013). It is used in the analysis of social and economic phenomena, not only in science and research, but also as an important instrument of state policy (Kadnár et al., 2014).

(6) 


\section{Aim of work}

\section{The research project is aiming to:}

- Establishment of quality standards tools to reduce the risk of association pneumonia in ICU at El-Mabarah Hospital.

- Application of select quality tools to reduce the risk of association pneumonia in ICU at El-Mabarah Hospital. 


\section{Methodology}

Methodology about implementation on reducing the risk of ventilator associated pneumonia at El mabarah Hospital in Port Said governorate by collecting data using Quality tools.

\section{Quality tools used in the study:}

\section{1- Check list}

\section{Definition:}

Checklist is type of job help used to reduce risk Failure by compensating for damages and set potential limits of human memory and draw the attention

Checklist is Tasks are accomplished based on a schedule that specifies the tasks to be performed according to the time of day or other Factors

A basic example is the 'to do list'. (7)

\section{Purpose $^{(8)}$}

Organization: Checklists help us implement tasks in a larger order and make sure we don't skip any step in the work and are also efficient and easy to use

Motivation: Checklists motivate us to complete tasks and carry out actions Productivity: By having a checklist, you can perform repetitive tasks faster, more efficiently, and with fewer errors.

Delegation: By breaking down tasks into specific task.

Excellence: Checklists allow us to deliver health care in an effective manner 
First : Check lists ${ }^{(9)}$

Name of Nurse /

Date of inspection

\begin{tabular}{|c|c|c|c|c|c|}
\hline $\begin{array}{c}\text { Items } \\
\text { /Description }\end{array}$ & Observation & Yes & No & N/A & Comments \\
\hline \multicolumn{6}{|c|}{ First:- general policy (PPE) } \\
\hline \multicolumn{6}{|c|}{$\begin{array}{l}1 \text { - Hands should be washed hygienically } \\
\text { before installing the laryngeal tube for a } \\
\text { patient }\end{array}$} \\
\hline \multicolumn{6}{|c|}{$\begin{array}{l}2 \text { - Hands should be washed routinely } \\
\text { between the patient and the other, and } \\
\text { dried thoroughly and the other }\end{array}$} \\
\hline \multicolumn{6}{|c|}{$\begin{array}{l}\text { 3- Gloves must be changed between the } \\
\text { patient and the patient }\end{array}$} \\
\hline \multicolumn{6}{|c|}{$\begin{array}{l}4 \text { - Protective clothing must be worn while } \\
\text { handling the patient }\end{array}$} \\
\hline \multicolumn{6}{|c|}{$\begin{array}{l}5-\text { A mask must be worn when dealing } \\
\text { with the patient or suctioning }\end{array}$} \\
\hline \multicolumn{6}{|c|}{ Second: - When caring for a patient connected to a respirator } \\
\hline \multicolumn{2}{|c|}{$\begin{array}{l}1 \text { - The patient's head and shoulders } \\
\text { should be placed at an angle of } 30 \text { to } 45 \\
\text { degrees }\end{array}$} & & & & \\
\hline \multicolumn{6}{|c|}{$\begin{array}{l}2 \text { - The fluid or any collection in the } \\
\text { laryngeal tube must be suctioned } \\
\text { periodically According to the patient's } \\
\text { condition, using a suction catheter new } \\
\text { every time }\end{array}$} \\
\hline \multicolumn{6}{|c|}{$\begin{array}{l}3 \text { - All connections of the respirator } \\
\text { between the patient and the other must be } \\
\text { changed to be sterilized or disinfected } \\
\text { before the next use }\end{array}$} \\
\hline $\begin{array}{l}4 \text { - All connectio } \\
\text { single patient mı } \\
\text { contaminated at }\end{array}$ & $\begin{array}{l}\text { he ventilator for a } \\
\text { changed and if } \\
\text { ne }\end{array}$ & & & & \\
\hline
\end{tabular}




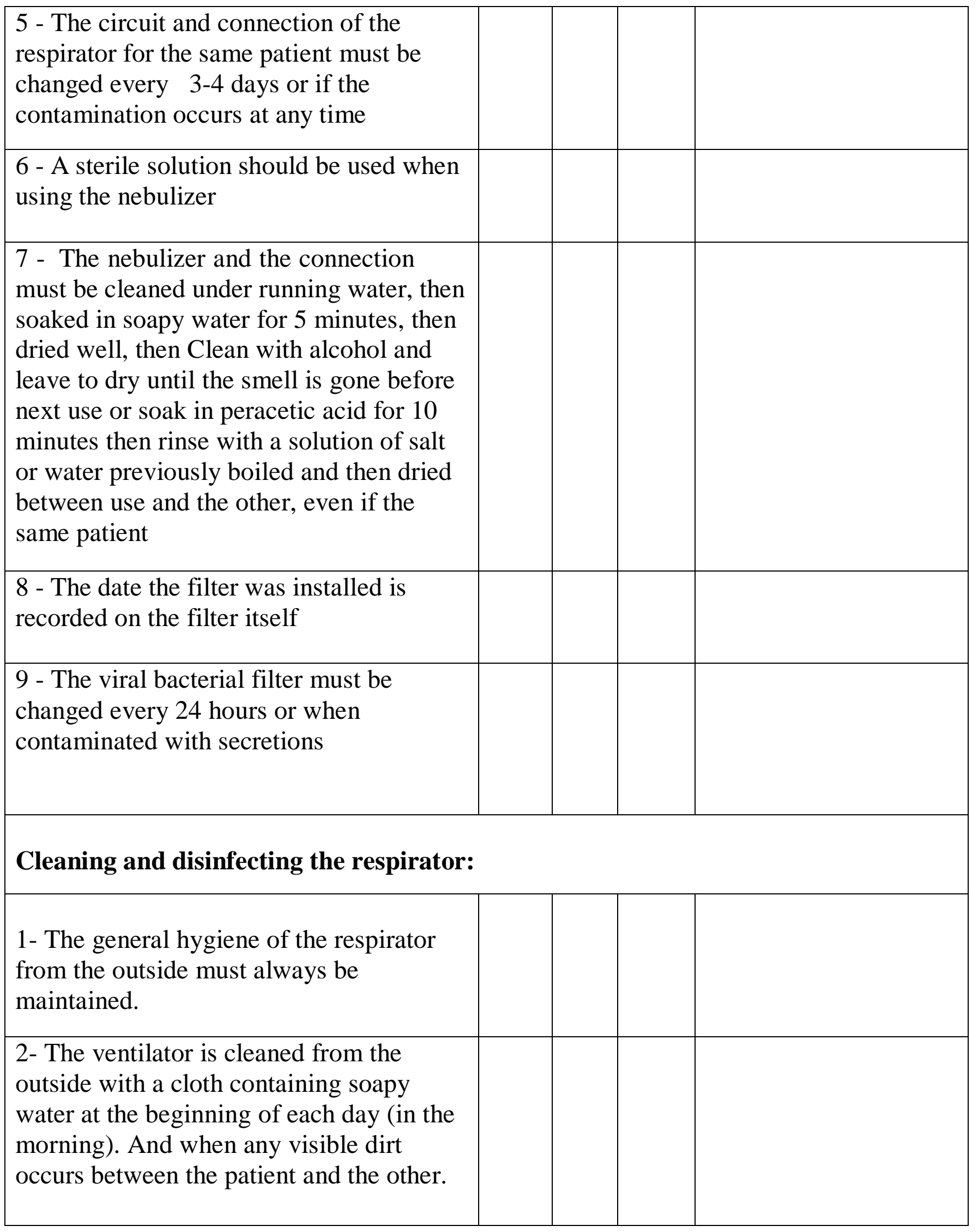




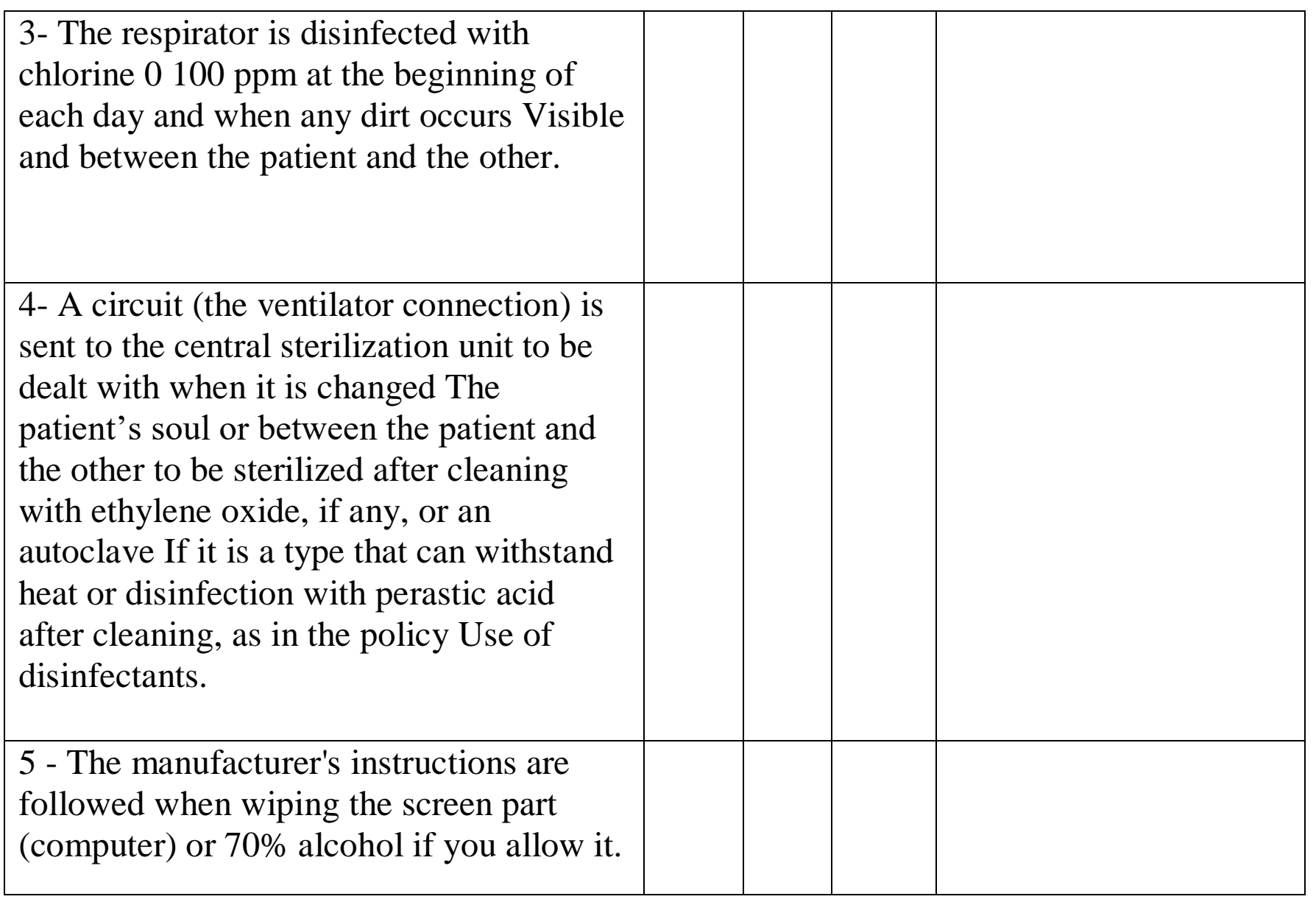

Table 1: checklist

\section{2 - Flow chart : ${ }^{(10)}$}

1- Allow all health care team to flow sequence of events in the process of services. 1

2- Show unexpected complexity, problems areas

3- 3. Compares and contrasts the actual VS the idea flow to identify improvement opportunist

4- 4 .Allow teams to come to an agreement

5- Identifies location where additional data are needed

6- Servese as training aid for understanding and completing the process. 
Second : Flow chart ${ }^{(11)}$

Pathogenic factors
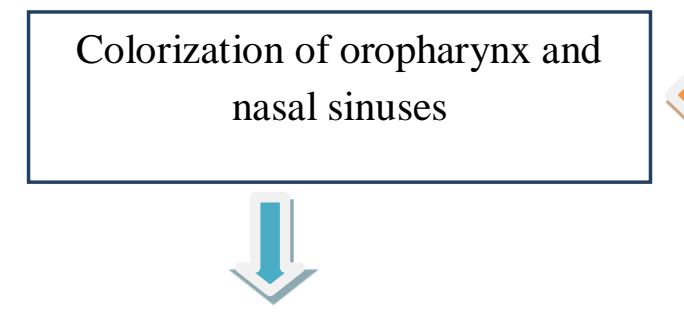

Exudate collects on the tracheal tube

Tracheal muscle injury by endotracheal tube

Microspiration of secretion pact the cuff
Biofilm formation within the endotracheal tube
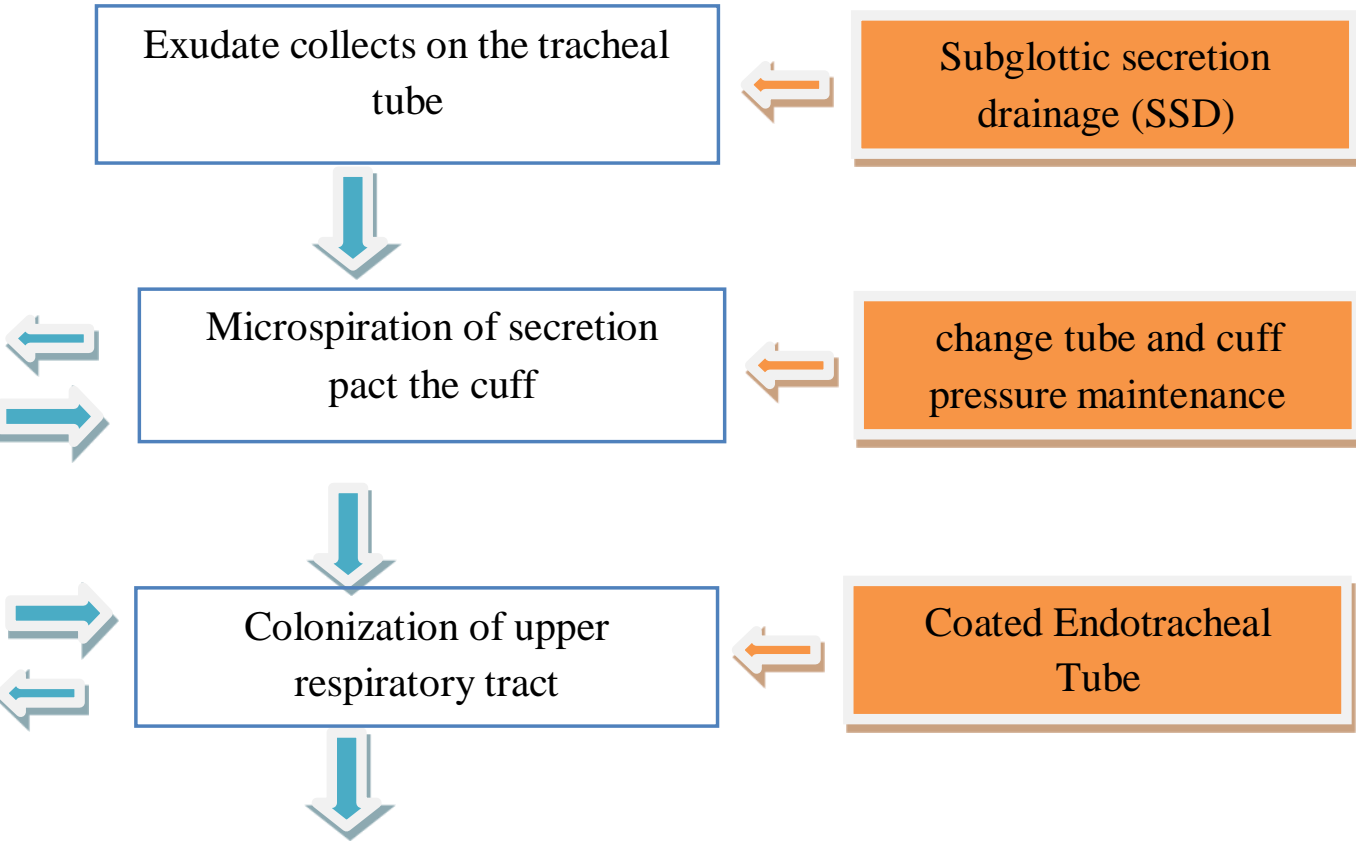

VAP prevention methods
Tooth-brushing \&

chlorhexidine $2 \%$ wash

\section{drainage (SSD)}

change tube and cuff pressure maintenance
Coated Endotracheal

Tube

Source: Zolfaghari and Wyncoll 2011

\section{Conclusion}

\section{This research concluded that}

- The prevalence of hospital acquired pneumonia due to decreased compliance of the medical team to the quality instructions \& techniques and sterilization

- Quality improvement focus primarily on efforts that would enhance the quality of care 
and customer outcomes

- $\quad$ Establishment of quality standards tools to reduce the risk of VAP in ICU

- Methods used to improve quality including - Regular assessing endotracheal Cuff pressure and frequent suctioning

- $\quad$ Avoid gastric distention and supine position

- $\quad$ regular hang cleaning of soap and alcohol

- Maintenance cuff pressure of endotracheal tube more than or $20 \mathrm{mmhg}$ reduce nosocomial pneumonia and decrease passage of orpharyngeal content into the trachea

- $\quad$ Oral intubation is prefer over nasal intubation

- The prevision methods usual on the research had decreased the VAP and increased the patient outcome and less mortality. 


\section{Recommendation}

From the conclusion of this research and after studying and using different quality tools, the following are recommended by this research group:

- The following points should be considered such as regular assessment of endotracheal cuff pressure, maintenance endotracheal suction aspiration procedure, avoide of gastric distension, and avoid the flat position

- Consideration should be given to treatment of modifiable agents such as tracheostomy and nasogastric tube, tracheostomy, re-intubation, enteral feeding, corticosteroid administration, gastric $\mathrm{pH}$-modifying agents, flat position, history of antibiotic use, absence of infection control practice, contaminated breathing equipment or medications or water.

- Maintenance cuff pressure at $20 \mathrm{~mm} \mathrm{Hg}$ to reduce VAP, This is by reducing the entry of the contents of the mouth and pharynx through the trachea

- The patient should be kept in a semi-seated position to reduce the risk of injury aspiration pneumonia

- Should be focus on Oral intubation over nasal intubation.

- Care should be taken to closely monitor the retained secretions and subsequent airway obstruction . Continuous suction of subglottic secretions through the tracheal tubes will reduce the incidence of VAP.

- Oral disinfection with chlorhexidine has been shown to reduce the incidence of VAP. 


\section{References:}

1. Kollef MH, Chastre J, Fagon JY, François B, Niederman MS, Rello J, Torres A, Vincent JL, Wunderink RG, Go KW, et al. Global prospective epidemiologic and surveillance study of ventilator-associated pneumonia due to Pseudomonas aeruginosa. Crit Care Med 2014;42: 2178-2187.

2. Melsen WG, Rovers MM, Groenwold RH, Bergmans DC, Camus C, Bauer TT, Hanisch EW, Klarin B, Koeman M, Krueger WA, et al. Attributable mortality of ventilator-associated pneumonia: a metaanalysis of individual patient data from randomised prevention studies. Lancet Infect Dis 2013;13:665-671.

3. Skrupky LP, McConnell K, Dallas J, Kollef MH. A comparison of ventilator-associated pneumonia rates as identified according to the National Healthcare Safety Network and American College of Chest Physicians criteria. Crit Care Med 2012;40:281-284.

4. Giuliano KK, Baker D, Quinn B. The epidemiology of non-ventilator hospital- acquired pneumonia in the United States. Am J Infect Control 2017

5. Finney JW, Willenbring ML, Moos RH (2000) Improving the quality of VA care for patients with substance-use disorders: the quality enhancement research initiative (QUERI) substance abuse module. Med Care 36:105-113.

6. KADNÁR, M. - RUSNÁK, J. - BUJNA, M. - VALÍČEK, J. KUŠNEROVÁ, M. - TÖKÖLY, P. 2014. Research of journal bearings for using in agricultural mobile machines In Research in Agricultural Engineering, vol. 60, 2014, special iss., pp. 25-30.

7. https://www.checkli.com last visited in last visited in 19-1-2021

8. Yahoo: First Person: How Checklists Improve Quality, Customer Satisfaction and Profits last visited in 19-1-2021.

9. National guide to infection control

10.Zolfaghari PS, Wyncoll DL (2011) The tracheal tube: gateway to 
ventilator-associated pneumonia. Crit Care, 15(5): 310.

11.Chong PS, Calingo L, Reynolds GL, Fisher DG (2003) Using an innovative approach to shorten coaching and assessment time when applying the Baldrige health care criteria for performance

excellence in a substance abuse treatment setting. Total Qual Manag Bus Excell 14(10):947-955.

12.Institute of Medicine (2001) Crossing the Quality Chasm: A New Health System for the 21st Century, Washington, DC: National Academies Press. 13.KORENKO, M. - KROČKO, V. - KAPLÍK, P. 2012. Use of FMEA method in manufacturing organization. In Manufacturing and Industrial Engineering, vol. 11, 2012, no. 2, pp. 48-50.

14. Koulenti D, Tsigou E, Rello J. Nosocomial pneumonia in 27 ICUs in Europe: perspectives from the EU-VAP/CAP study. Eur J Clin Microbiol Infect Dis 2016.

15.Lee SM, Lee DH, Kang CY (2012) The impact of high-performance work systems in

16.the health-care industry: employee reactions, service quality, customer satisfaction, and customer loyalty. Serv Ind J 32(1):17-36.

17. Melsen WG, Rovers MM, Groenwold RH, Bergmans DC, Camus C, Bauer TT, et al. Attributable mortality of ventilator-associated pneumonia: a meta- analysis of individual patient data from randomised prevention studies. Lancet Infect Dis 2013;13(8):665-71.

18. Prístavka, M., Beloev, C. I., \& Kročko, V. (2014). Quality control in production processes. Angel Kanchev University of Ruse, Bulgaria.

19. Prístavka, M., Beloev, C. I., \& Kročko, V. (2014). Quality control in production processes. Angel Kanchev University of Ruse, Bulgaria.

20. Raposo ML, Alves HM, Duarte PA (2009) Dimensions of service quality and satisfaction in healthcare: a patient's satisfaction index. Serv Bus: Int J 3(1):85-100.

21. Wunderink, R. G., C. G. Mayhall, and C. Gibert. 1992. Methodology for 
clinical investigation of ventilator-associated pneumonia. Epidemiology and therapeutic intervention. Chest 102:580S-588S. [PubMed] [Google Scholar]

216.

22. Wunderink, R. G., L. S. Woldenberg, J. Zeiss, C. M. Day, J. Ciemins, and D. A. Lacher. 1992. The radiologic diagnosis of autopsy-proven ventilator-associated pneumonia. Chest 101:458-463. [PubMed] [Google Scholar]

217.

23. Wysocki, M., F. Delatour, F. Faurisson, A. Rauss, Y. Pean, B. Misset, F. Thomas, J. F. Timsit, T. Similowski, H. Mentec, L. Mier, and D. Dreyfuss. 2001. Continuous versus intermittent infusion of vancomycin in severe staphylococcal infections: prospective multicenter randomized study. Antimicrob. Agents Chemother. 45:2460-2467. [PMC free article] [PubMed] [Google Scholar] 218.

24.Zack, J. E., T. Garrison, E. Trovillion, D. Clinkscale, C. M. Coopersmith, V. J. Fraser, and M. H. Kollef. 2002. Effect of an education program aimed at reducing the occurrence of ventilator-associated pneumonia. Crit. Care Med. 30:2407-2412. [PubMed] [Google Scholar] 219.

25.Zeitoun, S. S., A. L. de Barros, S. Diccini, and Y. Juliano. 2001. Incidence of ventilator-associated pneumonia in patients using open-suction systems and closed-suction systems: a prospective study-preliminary data. Rev. Lat. Am. Enfermagem 